\title{
Association of the Epstein-Barr virus latent membrane protein 1 with lipid rafts is mediated through its $\mathrm{N}$-terminal region
}

\author{
S. Rothenberger ${ }^{a, *}$, M. Rousseaux ${ }^{a}$, H. Knecht ${ }^{b}$, F. C. Bender ${ }^{a}$, D. F. Legler ${ }^{a}$ and C. Bron $^{a}$ \\ a Institute of Biochemistry, University of Lausanne, ch. des Boveresses 155, 1066 Epalinges (Switzerland), \\ Fax + 412169257 05, e-mail: Sylvia.RothenbergerAubert@ib.unil.ch \\ ${ }^{\mathrm{b}}$ Institute for Clinical Research, Swiss Paraplegic Center, 6207 Nottwill (Switzerland)
}

\begin{abstract}
The latent membrane protein 1 (LMP1) encoded by the Epstein-Barr virus acts like a constitutively activated receptor of the tumor necrosis factor receptor (TNFR) family and is enriched in lipid rafts. We showed that LMP1 is targeted to lipid rafts in transfected HEK 293 cells, and that the endogenous TNFR-associated factor 3 binds LMP1 and is recruited to lipid rafts upon LMP1 expression. An LMP1 mutant lacking the C-terminal 55 amino acids $(\mathrm{C} \Delta 55)$ behaves like the wild-type
\end{abstract}

Key words. LMP1; lipid rafts; TRAF3; TRAF2.

Epstein-Barr virus (EBV) is a ubiquitous lymphotropic herpesvirus that causes infectious mononucleosis and is consistently associated with nasopharyngeal carcinoma and large cell lymphomas of the immunocompromised host. EBV infection of B lymphocytes is mostly nonlytic. It results in the expression of a limited number of nuclear (Epstein-Barr nuclear antigens, EBNAs) or membrane (latent membrane proteins, LMPs) proteins, and in perpetual cell proliferation [1]. Although it has a well-known tropism for B lymphocytes and epithelial cells, EBV also infects T lymphocytes, monocytes and granulocytes [2]. The virus-encoded LMP1 is a major driving force in the process of neoplastic transformation. LMP1 is the only EBV product that has transforming ef-

\footnotetext{
* Corresponding author.
}

(WT) LMP1 with respect to membrane localization. In contrast, a mutant with a deletion of the $25 \mathrm{~N}$-terminal residues $(\mathrm{N} \Delta 25)$ does not concentrate in lipid rafts but still binds TRAF3, demonstrating that cell localization of LMP1 was not crucial for TRAF3 localization. Moreover, $\mathrm{N} \Delta 25$ inhibited WT LMP1-mediated induction of the transcription factors NF- $\mathrm{BB}$ and AP-1. Morphological data indicate that $\mathrm{N} \Delta 25$ hampers WT LMP1 plasma membrane localization, thus blocking LMP1 function.

fects on non-lymphoid cells [3, 4]. In lymphoid cells, LMP1 induces most of the phenotypic changes observed during EBV infection, including activation of NF- $\kappa \mathrm{B}$ and $\mathrm{Bcl}-2$, as well as up-regulation of adhesion molecules such as LFA-1 and ICAM-1 [5-7].

LMP1 is a constitutively active receptor-like molecule that alters cell growth [8]. In addition, it mimics CD40 [9] and engages signaling proteins of the tumor necrosis factor (TNF) family [10]. Finally, LMP1 is a powerful inducer of NF-kB-mediated transcription [11]. Two motifs are critical for cell transformation and activation of $\mathrm{NF}-\kappa \mathrm{B}$. The first, designated as the C-terminal activation region 1 (CTAR1), spans residues 199-231. It interacts with the TNF receptor-associated factors TRAF1, TRAF2, TRAF3 and TRAF5 [7, 12, 13]. TRAF2 activates NF- $\kappa \mathrm{B}$ by targeting the NF- $\kappa \mathrm{B}$-inducing kinase (NIK) followed by activation of the I $\kappa \mathrm{B} \alpha$ and I $\mathrm{I} \mathrm{B} \beta$ kinases [14]. 
The second motif, CTAR2, is located between residues $352-386[12,15]$. This region of LMP1 is thought to mediate NF- $\mathrm{BB}$ activation through direct binding of the TNF-associated death domain protein (TRADD) which then interacts with TRAF2, thus mimicking TNF receptor 1 (TNFR1)-mediated NF- $\kappa$ B activation $[16,17]$. This region is also linked to the activation of the AP-1 family of transcription factors through the c-Jun N-terminal kinase (JNK) pathway [18, 19].

LMP1 has been recently shown to partition in lipid rafts $[20,21]$. These specialized plasma membrane domains, enriched in sphingolipids and cholesterol preferentially incorporate proteins anchored via a glycosylphosphatidylinositol moiety, dually acylated proteins such as Src family kinases and $\alpha$ subunits of G proteins. Thus lipid rafts may function as signal transduction centers [22]. In fact, such a role for these membrane microdomains has been convincingly shown for immunoreceptor signaling in lymphopoietic cells [23-25]. Moreover, CD40, a member of the TNFR superfamily, compartmentalizes in lipid rafts following engagement with CD40L or specific antibodies [26, 27].

Several viruses have taken advantage of lipid rafts either to facilitate their assembly and budding, such as the measles virus [28] and the influenza virus [29], or to promote cell activation processes and facilitate virus replication and spread, such as the HIV-1 virus [30]. Some viral products, among them the influenza virus hemagglutinin [31], or the Nef-1 protein of HIV [30], have been shown to be directly associated with lipid rafts of their target cells.

Few proteins are enriched in lipid rafts. As shown for several adapter molecules, the addition of saturated fatty acids increases their affinity for lipid rafts. However, why some transmembrane proteins are also localized within lipid rafts is not yet clear. In particular, the reason for Epstein-Barr virus LMP1 protein targeting to lipid rafts is not known, nor the determinants necessary for such a distribution. In the present study, we analyzed the structural elements of LMP1 required for association with lipid rafts. Furthermore, we investigated the biological significance of this localization.

\section{Materials and methods}

\section{Antibodies}

Affinity-purified polyclonal rabbit anti-LMP1 antibody was a kind gift of Dr J. Martin, (MCD-Biology, University of Colorado, Boulder, Colo.). S12 monoclonal antibody against LMP1 [32] was a gift from Dr F. Meggetto (INSERM, Toulouse, France). Rabbit polyclonal antibody against caveolin-1 and mouse monoclonal antibodies against TRADD and RIP were from Transduction Laboratories (Lexington, Ky.). The rabbit polyclonal antibodies against TRAF2, TRAF3 and TRAF6 were from Santa Cruz biotechnology (Santa Cruz, Calif.). Polyclonal antibody against epidermal growth factor receptor (EGFR) was from Upstate Biotechnology (Lake Placid, N.Y.). Polyclonal antibody against Fyn was a gift from Dr Morris White, Harvard Medical School, Boston, Mass. Monoclonal antibodies against the transferrin receptor and caspase-3 were from Zymed and Signal Transduction, respectively.

\section{Plasmids}

Plasmids $\mathrm{pSV}_{2} \mathrm{BNLF}-1, \mathrm{C} \Delta 55, \mathrm{~N} \Delta 25$ and $3 \mathrm{x}-\mathrm{\kappa B}-\mathrm{L}$ have been described elsewhere $[33,34]$ and were the kind gift of Dr J. Martin (MCD-Biology). NF- $\mathrm{BB}-(3 \mathrm{x}-\kappa \mathrm{B}-\mathrm{L})$ [35] and AP-1 (pTRU14) [36] driven luciferase contructs were the kind gift of Dr B. Sugden (McArdle Laboratory for Cancer Research, University of Madison, Wis.), and Dr D. Bohman (EMBL, Heidelberg, Germany), respectively.

Plasmid pCR3-LMP1-GFP that allows the expression of LMP1 fused at its C terminus to the enhanced green fluorescent protein (EGFP) under control of a CMV promoter was constructed as follows. The cDNA sequence encoding full-lengh LMP1 was cloned into pCR3 (Stratagene, La Jolla, Calif.) by RT-PCR using the LMP1 primers 5'-CACAAGCTTGCCACCATGGAACAGACCTTG-3' and 5'-GAAGTCGACGTCATAGTAGCTTAG$3^{\prime}$ and RNA isolated from the lymphoblastoid cell lines B95-8 as template following standard methods (Pharmacia Biotech, Uppsala, Sweden). Then, EGFP sequence obtained by PCR amplification from plasmid pEGFP-C1 (Clonetech, Palo Alto, Calif.) to incorporate appropriate flanking restriction sites, was subcloned downstream of the LMP1 sequence. This construct was verified by sequencing. All plasmids were amplified and purified using either Quiagen (Quiagen, Hilden, Germany) or Jet star 2.0 Plasmid midi kits (Chemie Brunschwig, Basel, Switzerland).

\section{Cell culture and transfections}

The B95-8 lymphoblastoid cell line was obtained from Dr F. Meggetto (INSERM, Toulouse, France) and was grown at $37^{\circ} \mathrm{C}, 5 \% \mathrm{CO}_{2}$ in RPMI supplemented with $10 \%(\mathrm{v} / \mathrm{v})$ heat-inactivated fetal bovine serum and penicillin/streptomycin (all from Gibco Life Technologies, Basel, Switzerland). The human embryonic kidney cell line HEK 293 (ATCC CRL 1573) was grown at $37^{\circ} \mathrm{C}, 5 \%$ $\mathrm{CO}_{2}$ in DMEM supplemented with $10 \%(\mathrm{v} / \mathrm{v})$ heat-inactivated fetal bovine serum and penicillin/streptomycin. Cells were transfected using Fugene 6 (Roche Biochemicals, Rotkreuz, Switzerland) and analyzed $24 \mathrm{~h}$ later.

\section{Isolation of detergent-insoluble microdomains}

Lipid rafts were isolated by sucrose gradient fractionation in the presence of Triton X-100 as described elsewhere 
[37]. Briefly, HEK293 cells from one 15-cm-diameter subconfluent culture dish were lysed in $750 \mu \mathrm{l}$ of MNE buffer (25 mM MES, pH 6.5, $150 \mathrm{mM} \mathrm{NaCl,} 2 \mathrm{mM}$ EDTA) containing $1 \%$ Triton X-100 and $10 \mu \mathrm{g} / \mathrm{ml}$ benzamidine, $2 \mu \mathrm{g} / \mathrm{ml}$ antipain and $1 \mu \mathrm{g} / \mathrm{ml}$ leupeptin for $30 \mathrm{~min}$ on ice. Cells were further homogenized by ten gentle strokes of a loose-fitting pestle in a dounce homogenizer. The homogenate was mixed with $750 \mu 190 \%$ sucrose in MNE buffer. Overlaying sequentially $1.5 \mathrm{ml}$ $35 \%$ sucrose and $1.5 \mathrm{ml} \mathrm{5 \%}$ sucrose in MNE buffer formed a discontinuous sucrose gradient. The gradient was centrifuged at $120,000 \mathrm{~g}$ at $4{ }^{\circ} \mathrm{C}$ in a swinging bucket rotor SWT55 (Beckman, Palo Alto, Calif.). Twelve $370-\mu 1$ fractions were collected. Fraction 13 was obtained by sonicating the pellet present at the bottom of the gradient in $370 \mu \mathrm{l}$ MNE containing $1 \%$ Triton X-100. The amount of proteins in each fractions was determined using the BCA Protein Assay (Pierce, Rockford, Ill.).

\section{Cell lysis and immunoprecipitations}

Cells from 9-cm-diameter subconfluent culture dishes were harvested and lysed for $30 \mathrm{~min}$ on ice in CHAPS buffer (5 mM CHAPS, $10 \mathrm{mM}$ Tris-HCl pH 7.4, $0.15 \mathrm{mM}$ $\mathrm{NaCl}, 2 \mathrm{mM} \mathrm{MgCl}_{2}, 5 \mathrm{mM}$ EGTA) with protease inhibitors $(10 \mu \mathrm{g} / \mathrm{ml}$ benzamidine, $2 \mu \mathrm{g} / \mathrm{ml}$ antipain, $1 \mu \mathrm{g} / \mathrm{ml}$ leupeptin). The lysates were centrifuged for 5 min at $4{ }^{\circ} \mathrm{C}$ in an Eppendorf centrifuge to pellet nuclei. LMP1 was immunoprecipitated with S12 antibodies immobilized to protein A-Sepharose (Amersham Pharmacia Biotech, Uppsala, Sweden).

\section{Immunoprecipitation of LMP1 after sucrose gradient fractionation}

Lipid rafts from transfected or control cells were isolated by sucrose gradient fractionation. Fractions 3, 4 and 5 of the sucrose gradient were pooled and solubilized by the addition of one-tenth of $10 \times$ CHAPS buffer $(50 \mathrm{mM}$ CHAPS, $100 \mathrm{mM}$ Tris- $\mathrm{HCl} \mathrm{pH} 7.4,1.5 \mathrm{mM} \mathrm{NaCl}$, $20 \mathrm{mM} \mathrm{MgCl} 2,50 \mathrm{mM}$ EGTA) with protease inhibitors (10 $\mu \mathrm{g} / \mathrm{ml}$ benzamidine, $2 \mu \mathrm{g} / \mathrm{ml}$ antipain, $1 \mu \mathrm{g} / \mathrm{ml}$ leupeptin). LMP1 was immunoprecipitated with S12 antibodies immobilized to protein A-Sepharose (Amersham Pharmacia Biotech).

\section{Western blot analysis}

Proteins were separated by SDS-PAGE on $8 \%$ or $10 \%$ minigels (BioRad Laboratories, Glattbrugg, Switzerland) and transferred to Protran nitrocellulose membranes (Schleicher \& Schuell, Dassel, Germany). Membranes were blocked in PBS containing $0.05 \%$ Tween-20 and $3 \%$ dried milk and revealed using specific first antibodies followed by HRP-coupled second antibodies (BioRad, or Sigma, Buchs, Switzerland) and enhanced chemiluminescence (ECL) (Amersham Pharmacia Biotech, UK).

\section{Luciferase assays}

Luciferase activity in HEK293 cells was measured $24 \mathrm{~h}$ after transfection using reagents from the luciferase assay system (Promega, Wallisellen, Switzerland) according to the manufacturer's protocol. Lysis supernatants were incubated with excess luciferase substrate, and the light emitted was detected using a Lumac Biocounter M2500 (MBV, Stäfa, Switzerland). The data were normalized to the protein concentration of the samples and expressed as percentage of induction by wild-type (WT) LMP1.

\section{Confocal microscopy}

HEK293T cells were cultured for $24 \mathrm{~h}$ on chambered borosilicate coverglasses (Lab-TekII system; Nalge Nunc International, Naperville, Ill.) prior to transient transfection. Live cells expressing LMP1-GFP, in the presence or absence of $\mathrm{N} \Delta 25$ or $\mathrm{C} \Delta 55$, were directly analyzed by confocal microscopy (LSM510; Zeiss, Jena, Germany). GM1 gangliosides were visualized with Cy5-conjugated choleratoxin B subunit (CTx). A representative slice through the middle of the cell is shown. Cells expressing WT LMP1, N $\Delta 25$ or $\mathrm{C} \Delta 55$ were fixed with $3 \%$ paraformaldehyde in PBS for $10 \mathrm{~min}$ at room temperature, washed and permeabilized with $0.1 \%$ Triton X-100 in PBS for 10 min at room temperature. After blocking in PBS containing $0.5 \%$ bovine serum albumin for $30 \mathrm{~min}$ at room temperature, LMP1 constructs were stained with the anti-LMP1 monoclonal antibody S12 and anti-mouse $\mathrm{IgG}^{\mathrm{Cy} 3}$ (Milan Analytica, La Roche, Switzerland). Comparable localization was obtained when cells expressing LMP1-GFP were fixed, permeabilized and stained as the WT LMP1 construct.

\section{Subcellular fractionation}

Cells from a $15-\mathrm{cm}$ petri dish were washed twice in cold PBS and resuspended in $2 \mathrm{ml}$ homogenization buffer (250 mM sucrose, $20 \mathrm{mM}$ Tris- $\mathrm{HCl} \mathrm{pH}$ 7.4, $1 \mathrm{mM} \mathrm{MgCl}$, $1 \mathrm{mM} \mathrm{MnCl}_{2}, 1 \mathrm{mM}$ EDTA, plus $10 \mu \mathrm{g} / \mathrm{ml}$ benzamidine, $2 \mu \mathrm{g} / \mathrm{ml}$ antipain and $1 \mu \mathrm{g} / \mathrm{ml}$ leupeptin) for $20 \mathrm{~min}$ on ice. Cells were broken with 15 strockes of a tight-fitting pestle in a dounce homogenizer. The nuclei and unbroken cells were removed by low-speed centrigugation (1000 g for $10 \mathrm{~min}$ at $4^{\circ} \mathrm{C}$ ). The homogenates were centrifuged at $100,000 \mathrm{~g}$ at $4^{\circ} \mathrm{C}$ in a swinging bucket rotor SWT55 (Beckman, Palo Alto, Calif.). The pellets including cellular membranes were resuspended in $10 \mathrm{mM}$ Tris- $\mathrm{HCl} \mathrm{pH}$ $7.4,150 \mathrm{mM} \mathrm{NaCl}$. The proteins present in the highspeed supernatants (soluble fraction) were precipitated with chloroform:methanol and dissolved in the same volume of buffer. Both fractions were analyzed by SDS-PAGE. 


\section{Results}

\section{Deletion of the N-terminal region of LMP1} perturbs its localization in lipid rafts

One of the characteristics of lipid rafts is their partial resistance to solubilization by non-ionic detergents such as Triton X-100 in which they form glycolipid-enriched complexes at $4^{\circ} \mathrm{C}$. Due to their high lipid content, these membranes are of low buoyant density and can be isolated from mammalian cells by density gradient ultracentrifugation [38]. For our study, we used HEK293 cells that have previously proved very useful to assess LMP1 function $[34,35]$. We first analyzed the presence of LMP1 in lipid rafts from cells transfected with the plasmid $\mathrm{pSV}_{2} \mathrm{BNLF}-1$ coding for the prototype strain B95-8 LMP1, designated as WT. Figure 1 a shows LMP1 distribution in fractions collected after sucrose gradient centrifugation from the top (fraction 1) to the bottom (fraction 12) of the gradient. The remaining pellet was solubi-

a.

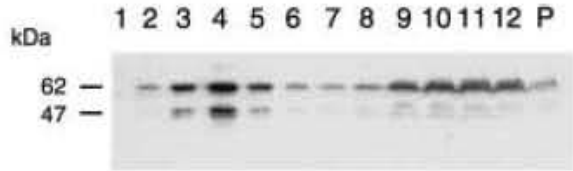

WT LMP1

b.

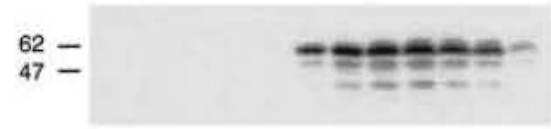

$\mathrm{N} \Delta 25$

c.

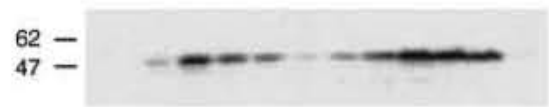

$\mathrm{C} \Delta 55$

d.

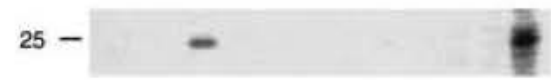

caveolin-1

e.

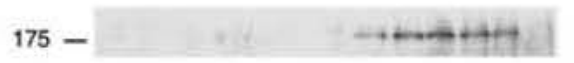

EGFR

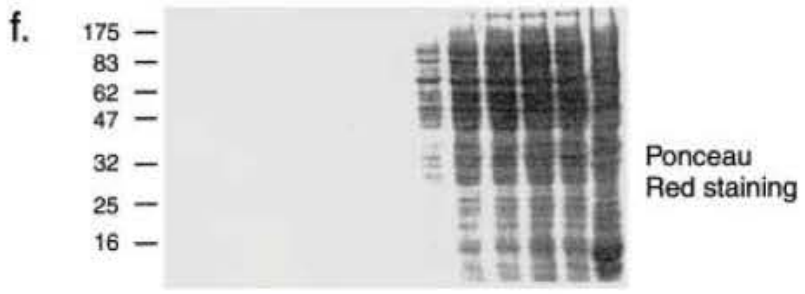

Figure 1. LMP1 is detected in low density fractions after sucrose gradient centrifugation. Lipid raft isolation from HEK293 cells transfected with expression vectors coding for either WT LMP1 (a), $\mathrm{N} \Delta 25(b)$ or $\mathrm{C} \Delta 55(c)$ was accomplished as described in Materials and methods. Aliquots $(15 \mu \mathrm{l})$ of the collected fractions were resolved on $10 \%$ SDS-PAGE and transferred to a nitrocellulose membrane. The membranes were Western blotted for LMP1 $(a-c)$, caveolin-1 $(d)$, or EGFR (e). A typical pattern of total protein distribution in a representative gradient from HEK293 cells is shown after Ponceau red $\mathrm{S}$ staining $(f)$ (P, pellet). lized in $1 \%$ Triton X-100, sonicated and analyzed by SDS-PAGE with the other fractions. LMP1 is clearly enriched in the low-density fractions $3-5$ of the gradient, reflecting lipid rafts. Upon expression in HEK293 cells, LMP1 migrates with an apparent molecular weight of $62 \mathrm{kDa}$. LMP1 has been shown to have a short half-life $[33,39,40]$, and the smaller LMP1 fragments which are detected in the blots are therefore likely to represent degradation products. A similar distribution of LMP1 in lipid rafts was observed in the EBV-transformed lymphoblastoid cell line B95-8 (data not shown).

To identify the elements required for LMP1 targeting to lipid rafts, we compared the membrane distribution of two deletion mutants, $\mathrm{N} \Delta 25$ and $\mathrm{C} \Delta 55$, to that of WT LMP1. In N $\Delta 25,25$ amino acids have been deleted from the $\mathrm{N}$ terminus, removing the complete $\mathrm{N}$-terminal cytoplasmic region. Surprisingly, we found that after extraction in Triton X-100 and flotation through a sucrose gradient that $\mathrm{N} \Delta 25$ was not enriched in lipid rafts (fig. $1 \mathrm{~b}$ ). In constrast, the mutant lacking the $\mathrm{C}$-terminal 55 amino acids $(\mathrm{C} \Delta 55)$ behaved like the WT LMP1 with respect to membrane distribution (fig. 1c). Caveolin-1, known to specifically partition in glycolipid- and cholesterol-rich microdomains, was exclusively present in the low-density fraction 4, as well as in the pellet (fig. 1d). In contrast, EGFR, which is excluded from lipid rafts under nonstimulatory conditions, was found in high-density fractions (fig. 1e). Most proteins were recovered in the highdensity fractions as shown by the Ponceau Red staining of the nitrocellulose membrane (fig. $1 \mathrm{f}$ ). We determined the protein content of each fraction and found that about $2 \%$ of the total proteins loaded on the gradient were recovered in fractions 1-5 (data not shown).

The membrane distribution of LMP1 constructs from several independent experiments are depicted in table 1, where the intensity of the signal present in the low-density fractions (fractions $1-5$ ), the high-density fractions (fractions 6-12) or the pellet was assessed by scanning the autoradiograms and expressed as a percentage of the

Table 1. Distribution of WT and mutant LMP1 after sucrose gradient centrifugation.

\begin{tabular}{lclll}
\hline & Fractions 1-5 & Fractions 6-12 & Pellet & n \\
\hline WT LMP1 & $37.8 \pm 1.3$ & $57.9 \pm 1.2$ & $4.3 \pm 0.1$ & 3 \\
N 25 & $2.5 \pm 3.2$ & $88.9 \pm 2.1$ & $8.6 \pm 5.4$ & 4 \\
C $\Delta 55$ & $32.7 \pm 4.2$ & $65.3 \pm 2.3$ & $2.0 \pm 2.0$ & 2 \\
\hline
\end{tabular}

The cells were transfected with expression vectors coding for either WT LMP1 (WT), N $\Delta 25$ or C $\Delta 55$. Distribution of the LMP1 mutants was analyzed after sucrose gradient centrifugation as described in Materials and methods. The immunoblots from several independent experiments were quantified using SCAN analysis. The reported values \pm SD represent the percentage of signal present in the low-density fractions (fractions 1-5), the high-density fractions (fractions 6-12) or the pellet ( $\mathrm{n}$, number of independent experiments). 


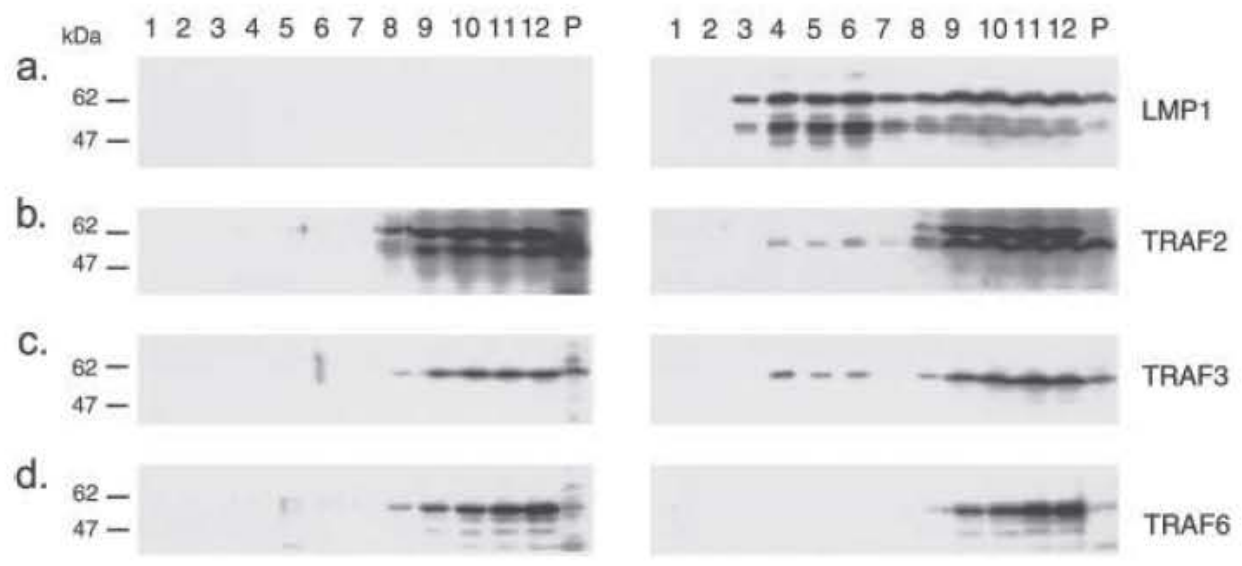

Figure 2. Expression of LMP1 induces the recruitment of TRAF3 to lipid rafts. Lipid raft isolation by density gradient from LMP1-transfected or untransfected HEK293 cells was accomplished as described in figure 1. Aliquots $(15 \mu \mathrm{l})$ of the collected fractions were resolved on $10 \%$ SDS-PAGE, transferred onto nitrocellulose membranes and analyzed by Western blotting for TRAF2, TRAF3, TRAF6 and LMP1.

total signal. Our results show that only $2.5 \%$ of $\mathrm{N} \Delta 25$ was recovered in low-density fractions, compared to about $38 \%$ of WT LMP1 and $32 \%$ of $\triangle 455$. These data indicate that $\mathrm{N} \Delta 25$ is not enriched in lipid rafts whereas the deletion of the C-terminus of LMP1 had no effect on the selective membrane localization of the protein.

\section{LMP1 recuits TRAF2 and TRAF3 to lipid rafts}

Genetic and biochemical analysis indicate that LMP1-induced activation of NF- $\mathrm{KB}$ is due to the interaction of LMP1 with TRAFs. To test whether the expression of LMP1 and its localization in lipid rafts leads to a redistribution of TRAFs, we expressed or not WT LMP1 in HEK293 cells, and analyzed the protein composition of lipid rafts and soluble fractions of Triton X-100-dispersed cell lysates separated by sucrose density gradients. Figure 2 a shows the distribution of WT LMP1 in the gradient. We observed that LMP1 recruited a very small but reproducible amount of TRAF2 to lipid rafts (fig. 2 b). However, the recruitment of TRAF3 to lipid rafts was more pronounced (fig. $2 \mathrm{c}$ ). In contrast, no recruitment of the unrelated TRAF6 was observed under the same conditions (fig. 2d). These results indicate that TRAF2 and TRAF3 are selectively recruited by LMP1 to lipid rafts.

\section{LMP1 binds TRAF3 in lipid rafts}

To determine whether lipid-raft-associated LMP1 binds TRAF3, sucrose gradient centrifugation experiments were performed with untransfected or LMP1-transfected cells. Fractions 3, 4 and 5 from the sucrose gradient were pooled and solubilized in CHAPS buffer. LMP1 was subsequently immunoprecipitated and the proteins resolved on SDS-PAGE. Western blot analysis of the samples revealed that TRAF3 co-immunoprecipitated with LMP1 (fig. 3). In contrast, under the same conditions, the protein kinase Fyn, which is highly abundant in these frac-

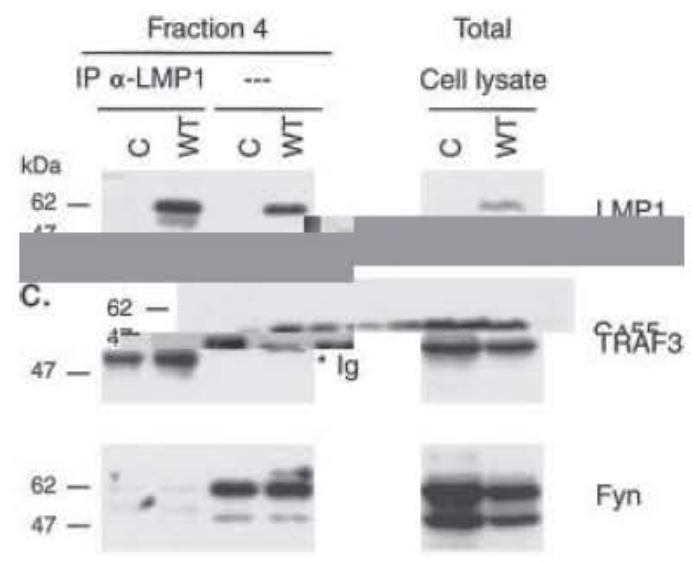

Figure 3. LMP1 isolated from lipid rafts binds TRAF3. Lipid rafts from either control cells (C) or cells transfected with WT LMP1 were isolated by density gradient as described in Materials and methods. LMP1 was subsequently immunoprecipitated from the low-density fractions 3,4 and 5, and the samples analyzed on $8 \%$ SDS-PAGE and transferred to nitrocellulose. LMP1, TRAF3 and Fyn were detected using the appropriate antibodies $\left({ }^{*} \mathrm{Ig}\right.$, position of the immunoglobulin heavy chain).

tions, was not co-immunoprecipitated with LMP1. These results demonstrate that the adapter molecule TRAF3 binds LMP1 in lipid rafts.

\section{Deletion of the N-terminal region of LMP1 does not prevent TRAF3 binding}

To test whether the binding of TRAF3 was affected if the N-terminal domain of LMP1 was deleted, we expressed WT LMP1, N $\Delta 25$ and C $\Delta 55$ in HEK293 cells, lysed the cells and immunoprecipitated LMP1. As shown by Western blot analysis, 57-kDa TRAF3 molecules were co-immunoprecipitated with WT LMP1 (fig. 4 a). In contrast, RIP or TRADD did not co-immunoprecipitate with WT LMP1 under the same conditions, a result confirmed 


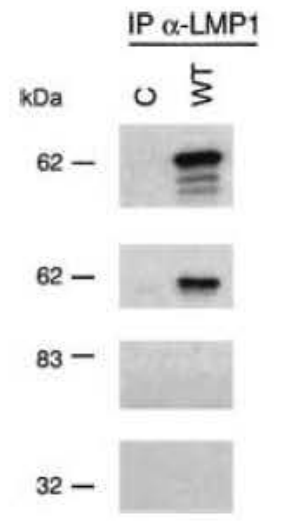

Cell lysate 0 々
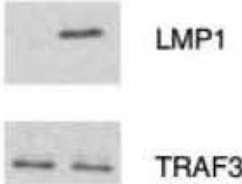

RIP

TRADD

b
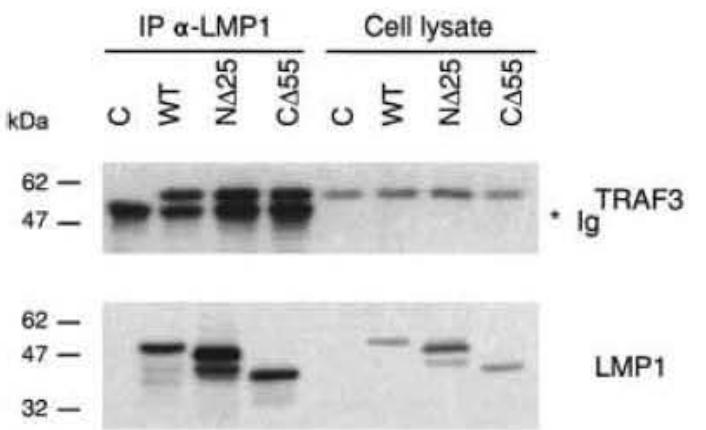

LMP1

Figure 4. TRAF3 is co-immunoprecipitated with WT LMP1, $\mathrm{N} \triangle 25$ and $\mathrm{C} \Delta 55$ in transfected HEK 293 cells. (a) Cells from 10 -cm petri dishes were transfected with $5 \mu \mathrm{g}$ of the expression vector coding for WT LMP1 (WT) or not transfected (C). LMP1 was immunoprecipitated with the S12 monoclonal antibody. One-fifth of the total sample was resolved on $8 \%$ SDS-PAGE and transferred to nitrocellulose membranes. LMP1, TRAF3, RIP and TRADD were detected by Western blotting using the appropriate rabbit polyclonal antibodies. (b) Cells from 10-cm petri dishes were transfected with the expression vectors coding for WT LMP1 (WT), N $\Delta 25$ or C $\Delta 55$. LMP1 was immunoprecipitated with the S12 monoclonal antibody. One-fifth of the total sample was resolved on $8 \%$ SDS-PAGE and transferred to nitrocellulose membranes. TRAF3 and LMP1 were detected by Western blotting using the appropriate rabbit polyclonal antibodies. Ten microliters of the cell lysates was analyzed simultaneously to detect the endogenous TRAF molecules and the transfected LMP1 forms in the samples ("Ig, position of the immunoglobulin heavy chain).

even when the cells were lysed in a buffer containing $0.5 \%$ Brij 58 , a non-ionic detergent known to have less dispersing effects on protein interactions than Triton X-100 or CHAPS (fig. 4a). TRAF3 was still co-immunoprecipitated with $\mathrm{N} \Delta 25$ and $\mathrm{C} \Delta 55$ (fig. $4 \mathrm{~b}$ ). These results indicate that TRAF3 still binds LMP1 when the N-terminal region is deleted.

$\mathrm{N} \Delta 25$ acts as a dominant negative variant of LMP1

Our results demonstrated that $\mathrm{N} \Delta 25$ is not targeted to lipid rafts, but still binds TRAF3 molecules. We therefore tested whether $\mathrm{N} \Delta 25$ could interfere with WT LMP1 signaling using NF- $\mathrm{kB}$ or AP-1 luciferase assays. As shown in an earlier work [35], $\mathrm{N} \Delta 25$ did not induce NF-kB-dependent luciferase activity in transfected

HEK293 cells and C $\Delta 55$ induced reporter expression only to $25 \%$ of the WT level (fig. 5a). Similarly, neither $\mathrm{N} \Delta 25$ nor $\mathrm{C} \Delta 55$ induced AP-1-dependent luciferase activity above background (fig. $5 \mathrm{~b}$ ). When $\mathrm{N} \Delta 25$ was co-transfected together with WT LMP1 in HEK293 cells, we observed a dose-dependent inhibition of both NF- $\mathrm{kB}$ and AP1-dependent luciferase activity (fig. $5 \mathrm{c}$, d). This inhibition was still detectable when cells were transfected with tenfold less plasmid coding for $\mathrm{N} \Delta 25$ than for the WT LMP1. In contrast, no negative effect on LMP1 signaling was observed even with equal amounts of transfected $\mathrm{C} \Delta 55$. Taken together, our results demonstrate that $\mathrm{N} \Delta 25$ acts as a dominant inhibitor of LMP1 signaling.

\section{N $\Delta 25$ alters the distribution of WT LMP1}

Several studies have previously shown a characteristic staining of LMP1 in punctuate and large patches by classical optical microscopy [32, 33, 41, 42]. In contrast to WT LMP1, various forms of LMP1 with deletions of 25,43 and 128 amino acids exhibited only diffuse fluorescence $[33,42,43]$. As expected, $\mathrm{N} \Delta 25$ showed a nonpatchy, diffuse distribution, whereas $\mathrm{C} \Delta 55$ distribution was similar to that of WT LMP1 (fig. 6a). To examine the mechanism of the dominant negative effect of $\mathrm{N} \Delta 25$, we constructed a fusion molecule between the WT LMP1 sequence and EGFP. We took advantage of the natural fluorescence of GFP to follow the distribution of LMP1 by confocal microscopy on viable cells, without fixing the cells or using antibodies. Several control experiments showed that the hybrid LMP1-GFP protein behaved like WT LMP1 with respect to membrane localization, showing characteristic patches at the plasma membrane (fig. 6b). Furthermore, the localization of LMP1-GFP did not change when cells were fixed and permeabilized (data not shown). In addition, in cells expressing LMP1GFP, staining with anti-LMP1 antibodies matched with the fluorescence derived from GFP (data not shown). Coexpression of LMP1-GFP with $\mathrm{N} \Delta 25$ clearly induced a redistribution of LMP1-GFP and prevented the formation of patches at the cell surface, while co-expression of $\mathrm{C} \triangle 55$ did not alter LMP1-GFP localization (fig. 6b). Vizualization of LMP1-GFP revealed that a portion of LMP1 localized at the plasma membrane with CTx (fig. 6b).

\section{$\mathrm{N} \Delta \mathbf{2 5}$ is membrane associated}

To test whether the deletion of the LMP1 N-terminal segment perturbs its membrane association, we compared the distribution of N $\triangle 25$ and WT LMP1 after subcellular fractionation (fig. 7). We detected both $\mathrm{N} \Delta 25$ and WT LMP1 in the high-speed pellet containing membrane proteins. The transmembrane transferrin receptor had a similar distribution, whereas the cytosolic caspase- 3 was detected in the high-speed supernatant only. 
a.

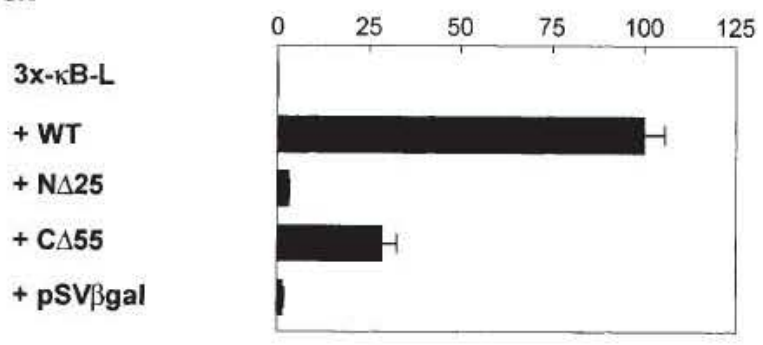

C.

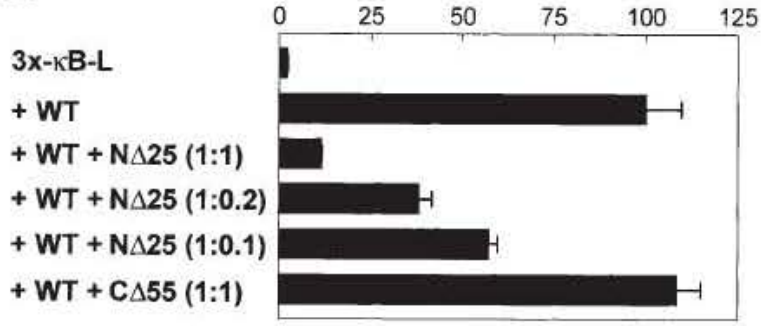

b.

$$
\begin{aligned}
& \text { pTRU14 } \\
& +W T \\
& +N \Delta 25 \\
& +C \Delta 55 \\
& +p S V B g a l
\end{aligned}
$$

AP-1

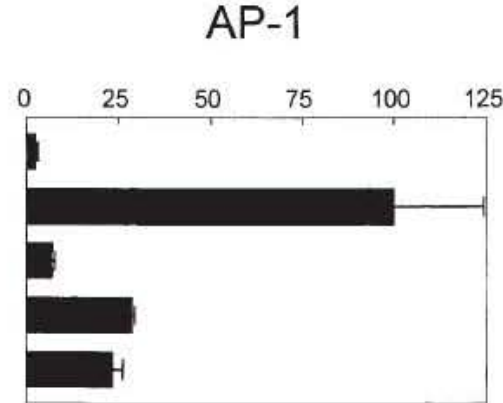

d.

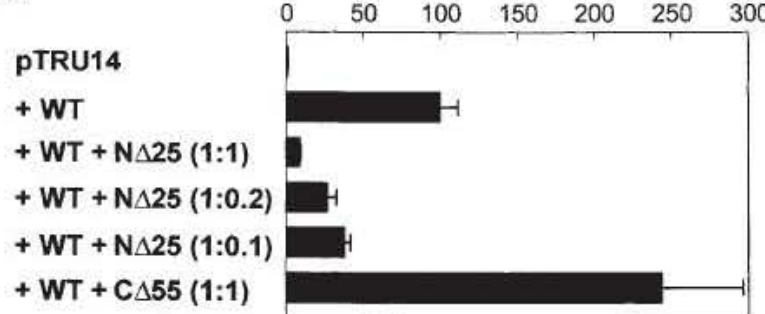

Figure 5. N $\triangle 25$ inhibits WT LMP1 signaling activities. Stimulation of NF-kB $(a, c)$ and AP-1 $(b, d)$ reporter activities by WT and deletion mutants of LMP1. Activation of NF- $\mathrm{kB}$ and AP-1 was determined by measuring the activity of the luciferase enzyme after co-transfecting the reporter plasmids $3 \mathrm{x}-\mathrm{kB}-\mathrm{L}(250 \mathrm{ng})$ and pTRU-14 $(50 \mathrm{ng})$, respectively, with $500 \mathrm{ng}$ pSV ${ }_{2} \mathrm{BNLF}-1$. As indicated N $\Delta 25$ was added at a $1: 1 \mathrm{ra}-$ tio to $\mathrm{pSV}_{2} \mathrm{BNLF}-1$ (500 $\mathrm{ng}$ of each plasmid), a 1:0.2 ratio (500 $\mathrm{ng} \mathrm{pSV}{ }_{2} \mathrm{BNLF}-1$ and $\left.100 \mathrm{ng} \mathrm{N} \Delta 25\right)$ or a 1:0.1 ratio (500 ng pSV ${ }_{2} \mathrm{BNLF}-1$ and $50 \mathrm{ng} \mathrm{N} \Delta 25)$. C $\Delta 55$ was added at a 1:1 ratio ( $500 \mathrm{ng}$ of each plasmid). All data were corrected for the protein content of each sample and are expressed as a percentage of the activity of WT LMP1. The experiments were repeated at least three times, with comparable results.
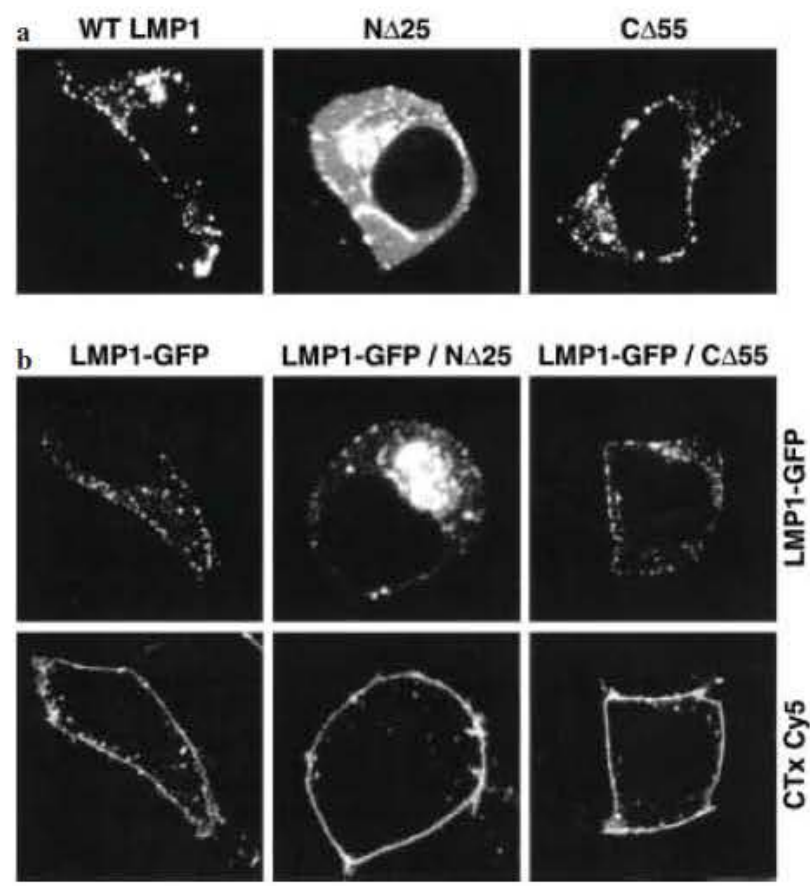

Figure 6. NA25 alters the distribution of WT LMP1. HEK293T cells were cultured for $24 \mathrm{~h}$ on chambered borosilicate coverglasses prior to transient transfection with $100 \mathrm{ng}$ of plasmid coding for WT LMP1 or C $\Delta 55$, and $20 \mathrm{ng}$ for plasmids coding for LMP1-GFP or $\mathrm{N} \Delta 25$. (a) Cells were fixed, permeablilized and stained with the anti-LMP1 monoclonal antibody $\mathrm{S} 12$ and anti-mouse $\mathrm{IgG}^{\mathrm{Cy}} 3$. (b) The fluorescence of LMP1-GFP was directly analyzed in live cells (top row); the same cells stained with $\mathrm{CTx}^{\mathrm{CY} 5}$ are shown below.

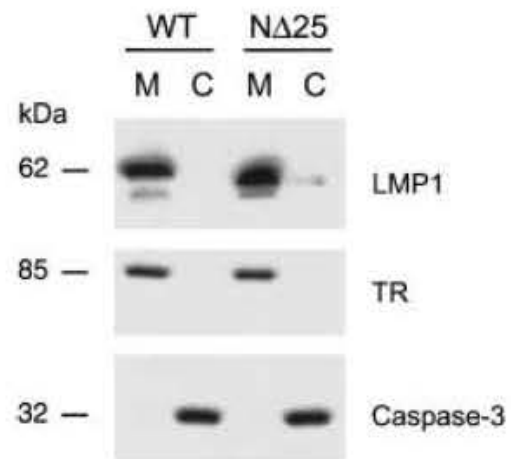

Figure 7. Cells from $15-\mathrm{cm}$ petri dishes were transfected with the expression vectors coding for WT LMP1 or N $\Delta 25$. The cells were homogenized and fractionated as described in Materials and methods. The proteins present in the high-speed pellet containing cellular membranes $(\mathrm{M})$ and the high-speed supernatant $(\mathrm{C})$ were analyzed on $10 \%$ SDS-PAGE. LMP1, the transferrin receptor (TR) and caspase- 3 were detected using the appropriate antibodies.

\section{Discussion}

We demonstrated in this study that an adapter molecule mediating an early step of signal transduction through LMP1 is associated with lipid rafts. We showed that (i) LMP1 binds to endogenous TRAF3 molecules in HEK293 cells and that (ii) TRAF3, and to a lesser extend TRAF2 are recruited to lipid rafts upon LMP1 expression. Our data are in agreement with recently published 
work demontrating that LMP1 is raft-associated and associated with TRAF3 in microdomains [21, 44]. These observations suggest that LMP1 has aquired multiple features of TNFR function, although the molecule shows no structural similarity to members of the TNFR family. However, CD40 recruits TRAF2 and TRAF3 to lipid rafts only after its engagement $[26,27]$. Since the localization of TRAF3 in the cell membrane is sufficient to convert this molecule to an activator of JNK [45], the translocation of TRAF molecules into lipid rafts seems to represent a key factor for signaling. In contrast to CD40, viral LMP1 partitions constitutively, i.e. without ligand binding or antibody cross-linking, in lipid rafts, where it recruits adapter molecules. The resulting effect is the constant activation of cellular pathways.

The mechanisms that determines lipid raft localization of LMP1 remains to be investigated. LMP1 was shown to be palmitoylated; however, this acylation is not necessary for the lipid raft association nor for the function of the protein [44]. We showed that the six transmembrane segments of LMP1 are not sufficient to direct the protein to lipid rafts. For correct targeting, the first 25 amino acids of the LMP1 N-terminal region play an essential role. This region may be important for self-aggregation, or may actively bind other cellular components. The presence of several proline residues in this region, which form potential SH3 domains involved in protein-protein interactions [46], supports this hypothesis. This sequence is also remarkably conserved between $\mathrm{EBV}$ isolates [S. Rothenberger, personal observations]. A mutational analysis of this region will provide more information on the structure requirements for LMP1 localization in lipid rafts.

In contrast to $\mathrm{N} \Delta 25$, the $\mathrm{C} \Delta 55$ deletion mutant, which has no CTAR2 site and therefore has lost the ability to activate the c-Jun pathway and whose activation of NF- $\mathrm{kB}$ is only $25 \%$ of the full-length form, partitions in lipid rafts as the WT LMP1. This indicates that the partitioning of LMP1 into membrane microdomains probably does not depend on the binding of adapter molecules. We also observed that the $\mathrm{N} \Delta 25$ deletion mutant, although unable to concentrate in lipid rafts, still binds adapter molecules. The binding of TRAFs seems therefore to be independent of the localization of LMP1. In contrast to LMP1, CD40 does not interact with TRAF molecules in the absence of stimulation with the CD40 ligand [27], suggesting that these interactions are restricted to lipid rafts. We further observed that $\mathrm{N} \Delta 25$ constitutes a dominant negative form of WT LMP1. This mutant may sequester TRAF molecules outside lipid rafts or maintain the full-length form in a conformation that does not allow the transmission of the signal. To test this hypothesis we constructed a chimera by fusing the LMP1 sequences to GFP. By confocal microscopy, this construct showed the same distribution as WT LMP1, with many visible aggregates and patches. This staining coincided with the distribution of WT LMP1 described previously using classical optical microscopy [32, 33, 41, 42] or, more recently, using a confocal microscope [47]. In agreement with these studies, a substantial amount of LMP1 was located in intracellular vesicles. Since LMP1 has a very short halflife $[33,40]$ and is degraded through the proteasome pathway [48], the mature LMP1 expressed at the plasma membrane is likely to represent only a minor fraction of the total amount present in the cell.

As expected from previous studies [33, 42, 49], N $\Delta 25$ showed a non-patchy, diffuse staining, whereas the $\mathrm{C} \Delta 55$ distribution was similar to WT LMP1. Co-expression of $\mathrm{N} \Delta 25$ clearly changed the distribution of LMP1-GFP, whereas $\mathrm{C} \Delta 55$ did not. These data suggest that $\mathrm{N} \Delta 25$ prevents the concentration of LMP1 in patches, explaining why it blocks LMP1 function. Although the deletion of the $25 \mathrm{~N}$-terminal amino acids may alter the folding and the transport of LMP1, it does not remove a signal sequence directing the protein to the membrane [50]. Furthermore, subcellular fractionation experiments showed that the deletion of 25 or even 43 N-terminal amino acids of LMP1 did not prevent the membrane association of the protein (fig. 7) [50]. Interestingly, the half-lives of LMP1 N-terminal deletion mutants were greatly prolonged compared to WT LMP1 [33, 48], an observation that rather argues against a major problem of misfolding in the endoplasmic reticulum.

Taken together, our results are consistent with a recent model proposing that after its synthesis, LMP1 translocates to the plasma membrane where it acquires a 'modification' that increases its affinity for TRAFs and lipid rafts, a 'modification' that is intrinsically encoded by the LMP1 N terminus [47]. In this report, the authors found that fusing the LMP1 N-terminus and membrane-spanning domains to the CD40 C-terminus supports signaling more efficiently than CD40 plus ligand or trimerized CD40. Our results suggest that the binding of TRAF3 does not depend on the localization of LMP1 in lipid rafts. Interestingly, the same region of LMP1, the cytoplasmic N-terminal domain, seems to be required for targeting to lipid rafts, ubiquitination and degradation. The elucidation of the role played by this region is likely to provide new information on the mechanism of signaling of other cell surface receptors.

Acknowledgements We would like to thank Drs B. Sugden and J. Martin for providing the plasmids $\mathrm{pSV}_{2} \mathrm{BNLF}-1, \mathrm{~N} \Delta 25, \mathrm{C} \Delta 55,3 \mathrm{x}-$ $\kappa B-L$ and the rabbit polyclonal antibody against LMP1. We thank Dr D. Bohman for the gift of plasmid pTRU14. We thank Dr F. Meggetto for providing the S12 monoclonal antibody against LMP1 and the lymphoblastoid cell line B95-8, and Dr J. Tschopp for the gift of the antibodies against RIP and TRADD. We thank Dr M. Nabholz for helpful suggestions and critical reading of the manuscript. The Swiss National Science Foundation (SNSF 31-61960.00) and the GiorgiCavalieri Foundation supported this work. 
1 Rickinson A. B. (1996) Epstein-Barr virus. In: Virology, pp. 2397-2446, Fields B. N., Knipe D. M and Howley P. M. (eds.), Lippincott-Raven, Philadelphia

2 Knecht H., Berger C., Rothenberger S., Odermatt B. and Brousset P. (2001) The role of Epstein-Barr virus in neoplastic transformation. Oncology 60: 289-302

3 Wang D., Liebowitz D. and Kieff E. (1985) An EBV membrane protein expressed in immortalized lymphocytes transforms established rodent cells. Cell 43: 831-40

4 Baichwal V. R. and Sugden B. (1988) Transformation of Balb $3 \mathrm{~T} 3$ cells by the BNLF-1 gene of Epstein-Barr virus. Oncogene 2: $461-467$

5 Rowe M., Peng-Pilon M., Huen D. S., Hardy R., Croom-Carter D., Lundgren E. et al. (1994) Upregulation of bcl-2 by the Epstein-Barr virus latent membrane protein LMP1: a B-cellspecific response that is delayed relative to NF-kappa B activation and to induction of cell surface markers. J. Virol. 68: $5602-5612$

6 Eliopoulos A. G. and Rickinson A. B. (1998) Epstein-Barr virus: LMP1 masquerades as an active receptor. Curr. Biol. 8: R196-R198

7 Devergne O., McFarland E. C., Mosialos G., Izumi K. M., Ware C. F. and Kieff E. (1998) Role of the TRAF binding site and NF-kappaB activation in Epstein-Barr virus latent membrane protein 1-induced cell gene expression. J. Virol. 72: 7900-7908

8 Cahir McFarland E. D., Izumi K. M. and Mosialos G. (1999) Epstein-Barr virus transformation: involvement of latent membrane protein 1-mediated activation of NF-kappaB. Oncogene 18: $6959-6964$

9 Kilger E., Kieser A., Baumann M. and Hammerschmidt W. (1998) Epstein-Barr virus-mediated B-cell proliferation is dependent upon latent membrane protein 1, which simulates an activated CD40 receptor. EMBO J. 17: 1700-1709

10 Mosialos G., Birkenbach M., Yalamanchili R., VanArsdale T., Ware C. and Kieff E. (1995) The Epstein-Barr virus transforming protein LMP1 engages signaling proteins for the tumor necrosis factor receptor family. Cell 80: 389-399

11 Hammarskjold M. L. and Simurda M. C. (1992) Epstein-Barr virus latent membrane protein transactivates the human immunodeficiency virus type 1 long terminal repeat through induction of NF-kappa B activity. J. Virol. 66: 6496-6501

12 Brodeur S. R., Cheng G., Baltimore D. and Thorley-Lawson D. A. (1997) Localization of the major NF-kappaB-activating site and the sole TRAF3 binding site of LMP-1 defines two distinct signaling motifs. J. Biol. Chem. 272: 19777-19784

13 Kaye K. M., Devergne O., Harada J. N., Izumi K. M., Yalamanchili R., Kieff E. et al. (1996) Tumor necrosis factor receptor associated factor 2 is a mediator of NF-kappa B activation by latent infection membrane protein 1, the Epstein-Barr virus transforming protein. Proc. Natl. Acad. Sci. USA 93: $11085-11090$

14 Sylla B. S., Hung S. C., Davidson D. M., Hatzivassiliou E., Malinin N. L., Wallach D. et al. (1998) Epstein-Barr virustransforming protein latent infection membrane protein 1 activates transcription factor NF-kappaB through a pathway that includes the NF-kappaB-inducing kinase and the IkappaB kinases IKKalpha and IKKbeta. Proc. Natl. Acad. Sci. USA 95 10106-10111

15 Sandberg M., Hammerschmidt W. and Sugden B. (1997) Characterization of LMP-1's association with TRAF1, TRAF2, and TRAF3. J. Virol. 71: 4649-4656

16 Izumi K. M., Kaye K. M. and Kieff E. D. (1997) The EpsteinBarr virus LMP1 amino acid sequence that engages tumor necrosis factor receptor associated factors is critical for primary B lymphocyte growth transformation. Proc. Natl. Acad. Sci. USA 94: 1447-1452

17 Izumi K. M., McFarland E. C., Ting A. T., Riley E. A., Seed B. and Kieff E. D. (1999) The Epstein-Barr virus oncoprotein la- tent membrane protein 1 engages the tumor necrosis factor receptor-associated proteins TRADD and receptor-interacting protein (RIP) but does not induce apoptosis or require RIP for NF-kappaB activation. Mol. Cell. Biol. 19: 5759-5767

18 Kieser A., Kilger E., Gires O., Ueffing M., Kolch W. and Hammerschmidt W. (1997) Epstein-Barr virus latent membrane protein-1 triggers AP-1 activity via the c-Jun N-terminal kinase cascade. EMBO J. 16: 6478-6485

19 Eliopoulos A. G. and Young L. S. (1998) Activation of the cJun $\mathrm{N}$-terminal kinase (JNK) pathway by the Epstein-Barr virusencoded latent membrane protein 1 (LMP1). Oncogene 16: $1731-1742$

20 Clausse B., Fizazi K., Walczak V., Tetaud C., Wiels J., Tursz T. et al. (1997) High concentration of the EBV latent membrane protein 1 in glycosphingolipid-rich complexes from both epithelial and lymphoid cells. Virology 228: 285-293

21 Ardila-Osorio H., Clausse B., Mishal Z., Wiels J., Tursz T. and Busson P. (1999) Evidence of LMP1-TRAF3 interactions in glycosphingolipid-rich complexes of lymphoblastoid and nasopharyngeal carcinoma cells. Int. J. Cancer 81: 645-649

22 Simons K. and Toomre D. (2000) Lipid rafts and signal transduction. Nat. Mol. Cell Biol. 1: 31-38

23 Ilangumaran S., He H. T. and Hoessli D. C. (2000) Microdomains in lymphocyte signalling: beyond GPI-anchored proteins. Immunol. Today 21: 2-7

24 Cherukuri A., Dykstra M. and Pierce S. K. (2001) Floating the raft hypothesis: lipid rafts play a role in immune cell activation. Immunity 14: 657-660

25 Lanzavecchia A. and Sallusto F. (2001) Antigen decoding by $\mathrm{T}$ lymphocytes: from synapses to fate determination. Nat. Immunol. 2: 487-492

26 Hostager B. S., Catlett I. M. and Bishop G. A. (2000) Recruitment of CD40 and tumor necrosis factor receptor-associated factors 2 and 3 to membrane microdomains during CD40 signaling. J. Biol. Chem. 275: 15392-15398

27 Vidalain P. O., Azocar O., Servet-Delprat C., RabourdinCombe C., Gerlier D. and Manie S. (2000) CD40 signaling in human dendritic cells is initiated within membrane rafts. EMBO J. 19: 3304-3313

28 Manie S. N., Debreyne S., Vincent S. and Gerlier D. (2000) Measles virus structural components are enriched into lipid raft microdomains: a potential cellular location for virus assembly. J. Virol. 74: 305-311

29 Scheiffele P., Rietveld A., Wilk T. and Simons K. (1999) Influenza viruses select ordered lipid domains during budding from the plasma membrane. J. Biol. Chem. 274: 2038-2044

30 Wang J. K., Kiyokawa E., Verdin E. and Trono D. (2000) The Nef protein of HIV-1 associates with rafts and primes T cells for activation. Proc. Natl. Acad. Sci. USA 97: 394-399

31 Scheiffele P., Roth M. G. and Simons K. (1997) Interaction of influenza virus haemagglutinin with sphingolipid-cholesterol membrane domains via its transmembrane domain. EMBO J. 16: $5501-5508$

32 Liebowitz D., Wang D. and Kieff E. (1986) Orientation and patching of the latent infection membrane protein encoded by Epstein-Barr virus. J. Virol. 58: 233-237

33 Martin J. and Sugden B. (1991) Transformation by the oncogenic latent membrane protein correlates with its rapid turnover, membrane localization, and cytoskeletal association. J. Virol. 65: 3246-3258

34 Rothenberger S., Bachmann E., Berger C., McQuain C., Odermatt B. F. and Knecht H. (1997) Natural 30 base pair and 69 base pair deletion variants of the LMP1 oncogene do stimulate NF-kappaB-mediated transcription. Oncogene 14: $2123-2126$

35 Mitchell T. and Sugden B. (1995) Stimulation of NF-kappa B-mediated transcription by mutant derivatives of the latent membrane protein of Epstein-Barr virus. J. Virol. 69: 2968-2976 
36 Kieser A., Seitz T., Adler H. S., Coffer P., Kremmer E., Crespo P. et al. (1996) Protein kinase C-zeta reverts v-raf transformation of NIH-3T3 cells. Genes Dev. 10: 1455-1466

37 Lisanti M. P., Scherer P. E., Vidugiriene J., Tang Z., Hermanowski-Vosatka A., Tu Y. H. et al. (1994) Characterization of caveolin-rich membrane domains isolated from an endothelial-rich source: implications for human disease. J. Cell. Biol. 126: $111-126$

38 Brown D. A. and London E. (1998) Functions of lipid rafts in biological membranes. Annu. Rev. Cell. Dev. Biol. 14: 111136

39 Baichwal V. R. and Sugden B. (1987) Posttranslational processing of an Epstein-Barr virus-encoded membrane protein expressed in cells transformed by Epstein-Barr virus. J. Virol. 61: $866-875$

40 Mann K. P. and Thorley-Lawson D. (1987) Posttranslational processing of the Epstein-Barr virus-encoded p63/LMP protein. J. Virol. 61: 2100-2108

41 Izumi K. M., Kaye K. M. and Kieff E. D. (1994) Epstein-Barr virus recombinant molecular genetic analysis of the LMP1 amino-terminal cytoplasmic domain reveals a probable structural role, with no component essential for primary B-lymphocyte growth transformation. J. Virol. 68: 4369-4376

42 Bloss T., Kaykas A. and Sugden B. (1999) Dissociation of patching by latent membrane protein-1 of Epstein-Barr virus from its stimulation of NF-kappaB activity. J. Gen. Virol. 80: 3227-3232

43 Wang D., Liebowitz D. and Kieff E. (1988) The truncated form of the Epstein-Barr virus latent-infection membrane protein expressed in virus replication does not transform rodent fibroblasts. J. Virol. 62: 2337-2346
44 Higuchi M., Izumi K. M. and Kieff E. (2001) Epstein-Barr virus latent-infection membrane proteins are palmitoylated and raft-associated: protein 1 binds to the cytoskeleton through TNF receptor cytoplasmic factors. Proc. Natl. Acad. Sci. USA 98: $4675-4680$

45 Dadgostar H. and Cheng G. (2000) Membrane localization of TRAF 3 enables JNK activation. J. Biol. Chem. 275: 2539-2544

46 Kay B. K., Williamson M. P. and Sudol M. (2000) The importance of being proline: the interaction of proline-rich motifs in signaling proteins with their cognate domains. FASEB J. 14: 231-241

47 Kaykas A., Worringer K. and Sugden B. (2001) CD40 and LMP-1 both signal from lipid rafts but LMP-1 assembles a distinct, more efficient signaling complex. EMBO J. 20: $2641-2654$

48 Aviel S., Winberg G., Massucci M. and Ciechanover A. (2000) Degradation of the Epstein-Barr virus latent membrane protein 1 (LMP1) by the ubiquitin-proteasome pathway. Targeting via ubiquitination of the N-terminal residue. J. Biol. Chem. 275: 23491-23499

49 Wang D., Liebowitz D., Wang F., Gregory C., Rickinson A., Larson R. et al. (1988) Epstein-Barr virus latent infection membrane protein alters the human B-lymphocyte phenotype: deletion of the amino terminus abolishes activity. J. Virol. 62: $4173-4184$

50 Baichwal V. R. and Sugden B. (1989) The multiple membranespanning segments of the BNLF-1 oncogene from Epstein-Barr virus are required for transformation. Oncogene 4: 67-74 